\title{
Using Business Simulations As Authentic Assessment Tools
}

Pat Neely, Ashford University, USA

Jan Tucker, Ashford University, USA

\begin{abstract}
New modalities for assessing student learning exist as a result of advances in computer technology. Conventional measurement practices have been transformed into computer based testing. Although current testing replicates assessment processes used in college classrooms, a greater opportunity exists to use computer technology to create authentic assessments. Assessments that mirror real world scenarios and often teach and enhance skill building while measuring student achievement. This case study examines the evaluation of business simulations as authentic assessment instruments using the five dimensions of authenticity developed by Gulikers, Bastiaens and Kirschner (2004). The paper will conclude with a review of business simulations available in the marketplace.
\end{abstract}

Keywords: Simulations; Student Learning; Assessment; Authentic Assessment; Evaluation; Course Outcomes

\section{INTRODUCTION}

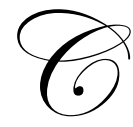

alls for greater accountability in higher education continue to be featured in the news as the cost of a college education rises faster than inflation. Amidst the calls for greater accountability, criticisms of poorly prepared business graduates resonates throughout business meetings and in business journals. The need for students to go beyond recalling facts and to demonstrate reasoning, problem solving ability, and creative and innovative approaches to business problems is clear (Shavelson, Baxxter, \& Pine, 1991). In the United States, several federal laws and government regulations require that colleges and universities demonstrate that they are preparing students for employment. Title IV of the Higher Education Act of 1965, along with the Higher Education Opportunity Act passed in 2008, address the need for colleges and universities to prepare students for gainful employment in a recognized occupation (Epstein, 2010). Higher education professionals are anticipating major changes to the law in 2013 with the renewal of the Higher Education Act

Since the 1990s, there have been numerous advocates of authentic assessment as one of the critical pieces necessary to help students learn (Wiggins \& McTighe, 1998; Leahy, et al., 2005, Johnson, 2007). New calls for accountability in higher education include developing methods and practices for assessing outcomes at the institutional, program, and course levels. The focus on skills indicate there is a gap between the skills employers identify as being important for first time job seekers and the skills that colleges focus on in the classroom (Gabric \& McFadden, 2001). In order to address the gap, curriculum should be redesigned to include applied skills, such as problem-solving, communication, and analytical skills. Owyang (2010) reports that a survey conducted by the Altimeter group found that the number one skill employers wanted for new business graduates was real world business experience. Calls for authentic assessment methods have increased in response to the perceived need for teaching applied skills to business students.

Student outcomes assessment continues to receive attention from external constituencies regarding the level of skills students can demonstrate in the workplace and across varying type of institutions. Higher education researchers and curriculum designers are focusing on authentic assessment techniques and backward design whereby curriculum is designed and assessed based on the skills a graduate is expected to demonstrate on their first job after earning their degree (Palm, 2008). Authentic assessment requires students to use prior learning, recent studies, and relevant skills to solve realistic and often complex problems (DiMartino \& Castaneda, 2007). Passing a multiple- 
choice test or writing an essay demonstrates an understanding of the acquisition of knowledge. These assessment techniques fall short of having students demonstrate what they can do with the knowledge learned in a course or program. Employers of business graduates are looking for graduates with business experience and proven leadership and communication skills (Germain, 2009).

The traditional static educational model of instructors delivering lectures and assessing student learning using multiple-choice and essay exams is designed to measure knowledge, not to have students actually solve authentic tasks that solve real-life problems (Gulikers, Bastiaens, and Kirschner, 2004). This paper explores the question becomes how to adequately assess whether college graduates have attained the skills and competencies they need to become employed in their field of study by examining the historical use of simulations and whether simulations can be used for authentic assessment in addition to their use as learning tools.

\section{COMPUTER BASED SIMULATIONS}

Real world scenarios designed to imitate activities that professionals perform in their everyday jobs are the basis for simulations. When designed properly, the simulations require the same type of activities performed in the work place. Medical and aviation schools were early adopters of simulation type training to prepare practitioners in those fields (Jeffries, 2005). Medical students use simulations to hone their surgical skills on computerized mannequins before working with live patients. Spinello and Fischbach (2004) used problem based learning to develop an interactive online public health simulation to provide opportunities for public health students to practice decision making in a safe environment. Studies have shown that simulations not only improve the efficiency of healthcare workers but they are also effective recruiting tools (Heather, 2010; Rieber, Betz, Muth, Nikendei, Schrauth, \& et al., 2009). Aviation students receive training in flight simulators to perfect their flight skills prior to manning an aircraft. Bell and Waag (1998) point out that simulations to train fighter pilots improved pilot readiness for in flight training.

Simulations and gaming applications, as well as social networking, are gaining acceptance in the higher education arena. Increased use of simulations in the non-health and aviation classrooms is evident by the proliferation of simulations and educational games available on the internet. Early data from several studies supports the value of scenario based learning. Students in a sports management class were asked to compare a traditional lecture-based classroom to a classroom utilizing simulations in place of lectures. The results indicated that not only did students prefer the learning simulation environment but they also spent more time outside of the classroom preparing for the simulation classes than the lecture classes (Newman, Irwin, Klenosky, \& Gillentine, 2003). The addition of the integration of multimedia, including simulations, into the online and on ground college classroom can be used to attract and retain the attention of students. Research has shown that when students are engaged in what they are studying, they comprehend the material at a deeper, more cognizant level (Tan, Tse, \& Chung, 2010). Klassen and Willoughby (2003) evaluated learning by simulations by issuing a questionnaire to students prior to beginning a simulation on inventory systems and again after the student had played the simulation. Most of the results indicated that students did in fact learn by participating in the simulation. In addition, many students reported that they not only enjoyed the learning experience but found it a worthwhile endeavor (2003).

The role of instructors in facilitating simulations effectively in the classroom is to provide feedback to the learner and increase repetitive practice. Adapting to various learning strategies is an important factor to the success of simulations in the classroom (Spillane, 2006). While previous research supports the idea of using simulations to facilitate learning, the authors were interested in whether simulations can be used to actually assess student learning.

\section{BUSINESS PROGRAMS AND SIMULATIONS}

Business program development occurs during phases with ongoing program maintenance and major redevelopment efforts occuring approximately every four years. During 2009, administrators in the college of business administration began the program review process and determined that rather than continue with making small changes to the current business curriculum, it was time for a major redesign of the business curriculum. One problem that had been identified with the existing program was an over-reliance on traditional assessment methods. Written projects and multiple-choice assessments were the sole methods of evaluating student learning. In terms of Bloom's taxonomy, the focus was on declarative learning at the lower end of the scale (Nilson, 2003). The 
assessments used in the program were also outdated. Many of the summative assessments had been developed when the program was created in 2006. University Administrators, Advisory Board Members, and the Business Faculty wanted to integrate authentic tasks in the program. A focus group of business leaders also emphasized the need for business graduates to have real-life problems solving skills.

Authentic assessment is seen by some researchers as being performance assessments, while others see authentic assessment as going beyond just performance tasks and asking students to perform realistic tasks in a realistic context (Gulikers, Bastiaens \& Kirschner, 2004). In order to determine the best methods for assessing student learning, the committee reviewed the competencies and objectives and evaluated various assessment methods currently used for their validity as authentic assessment instruments. Multiple choice exams, essays, papers, projects, case studies and presentations were currently used to assess student achievement.

Creating more authentic, real-world tasks as assessments in the business program required looking at computer-based testing and business simulations currently available in the marketplace. After the business competencies were identified, a faculty committee began the process of identifying and evaluating simulations for use as assessments in the program. Textbook companies were contacted along with other suppliers of education content. Reviews of simulations used in business training in the corporate world were reviewed.

\section{THE STUDY}

Before the study could begin, the faculty committee and university administrators finalized the program level competencies and objectives that would be demonstrated by business graduates. The faculty committee including subject matter experts in accounting and finance, quantitative analysis, marketing, management, business law, economics, and information technology, examined the learning outcomes to identify areas where simulations may be available to measure student mastery of the competencies. An environmental scan was completed where the committee searched for business simulations that were currently available in the marketplace. This qualitative study examines the simulations identified using the five dimensions of authentic assessment as identified by Gulikers, Bastiaens and Kirschner (2006).

Guiding the researchers' study of simulations were four questions:

1. What types of business simulations are available in the marketplace?

2. How do the available simulations align with program competencies and objectives?

3. Can the simulations be used to assess business competence?

4. How can the evaluation process be improved when evaluating future assessment options?

Examinations of the faculty committee's work began with the gathering of evidence from committee meetings and correspondence. The examination was twofold: First, each item was analyzed to determine how it demonstrated group process. Group interactions were evaluated using the effectiveness criteria established by Robbins and Judge (2007) for interacting groups. The level of task orientation, amount of interpersonal conflict, commitment to developing a solution, group cohesiveness, and speed of decision-making were examined. Second, each document was scored using the five dimensions of authentic assessment checklist provided in Table 1.

\section{FINDINGS}

An analysis of 192 e-mails regarding the business program development (102 of which pertained directly to the simulations) were examined and revealed that the review of simulations began in 2009 and continued into early 2010. Faculty members working in the College of Business and assessment department staff were asked to identify simulations that might be appropriate for use in the revise program. In June 2009, a curriculum committee of seven individuals was formed and tasked with summarizing the information gathered and developing a list of possible simulations to be used as summative assessments in the business program.

Over the course of eight months, seventeen off-the-shelf business simulations were examined. The simulations examined included a variety of products from several diverse providers. Simulations from publishers, 
like McGraw-Hill and Pearson, were evaluated as were simulations from technology companies such as GoVentures and CapSim. Individuals on the committee were assigned simulations and asked to perform a cursory review and provide feedback to the committee.

The project manager developed an analysis checklist for examining the selected simulations. Committee members were asked to evaluate a series of questions on a scale of 1-5 with 1 meaning the simulation does not satisfy the requirement and 5 meaning it completely satisfies the requirement. The committee completed the evaluation of simulations using the simulation checklist that was developed. Only one simulation included a final comprehensive exam. The items the committee members were to evaluate as they reviewed the simulations for use in the business program are presented in Table 2.

Table 1: Authentic Assessment Frequency Table

Research Item:

Date:

\begin{tabular}{|l|l|}
\hline \multicolumn{1}{|c|}{ Dimensions } & Frequency \\
\hline Task Criterion & \\
\hline Meaningfulness and relevance in the students' eyes & \\
\hline Degree of ownership of problem and solution & \\
\hline Criterion at the students' educational level & \\
\hline Structure of task is well-defined & \\
\hline Monodisciplinary/Multidisciplinary & \\
\hline Physical Context & \\
\hline Similar to professional work space & \\
\hline Availability of professional resources & \\
\hline Similarity to professional time frame & \\
\hline Social Context & \\
\hline Individual work/decision-making & \\
\hline Groups or collaborative work/decision-making & \\
\hline Result/Form & \\
\hline Demonstration of competence & \\
\hline Presentation to others & \\
\hline Multiple indicators of learning & \\
\hline Criteria & \\
\hline Based on criteria in professional practice & \\
\hline Related to realistic products/processes & \\
\hline Transparent and explicit & \\
\hline Criterion-referenced leading to profile score & \\
\hline
\end{tabular}

Table 2: Ratings Checklist

\begin{tabular}{|l|l|}
\hline \multicolumn{1}{|c|}{ Item } & Scale 1-5 \\
\hline Ease of use & \\
\hline Ease of administration & \\
\hline Learning materials & \\
\hline Alignment of learning resources and tasks in simulation & \\
\hline Record of outputs & \\
\hline Detailed feedback on student performance & \\
\hline Flexible pacing & \\
\hline Compartmentalized content & \\
\hline Activities align with program and course objectives & \\
\hline Reasonable per student costs & \\
\hline
\end{tabular}

After several general discussions, as evidenced by the e-mail correspondence and the review of the minutes of the meetings, six simulations out of the 17 originally reviewed were selected for an in-depth review. Based on feedback from committee members, many of the simulations were determined to be inappropriate for a graduatelevel program, were too complicated to operate, did not produce the warranted outcomes, or were too costly. Those simulations were not selected for an in-depth review. The six simulations chosen for further review and the committee members' cumulative scores are presented in Table 3. 
Table 3: Simulations and Scores for Further Review

\begin{tabular}{|c|c|c|c|c|c|c|}
\hline Simulation Provider & Capsim & McGraw-Hill & IntelliSIM & SimuLearn & Media Spark & Espire Learning \\
\hline Simulation Name & Capsim & $\begin{array}{c}\text { Business } \\
\text { Strategy Game }\end{array}$ & $\begin{array}{c}\text { Global } \\
\text { Tycoon }\end{array}$ & $\begin{array}{l}\text { Virtual } \\
\text { Leader } \\
\end{array}$ & Go Ventures & $\begin{array}{l}\text { Executive } \\
\text { Challenge } \\
\end{array}$ \\
\hline Average Score: & 3.73 & 3.8 & 2.43 & 3.31 & 3.86 & 2.9 \\
\hline Total Score out of 50 & 37.3 & 38.0 & 24.3 & 33.1 & 38.6 & 29.0 \\
\hline
\end{tabular}

The simulations review process got off to a slow start as the team tried to identify simulations available in the marketplace. Web searches revealed few usable simulations. Conversations with colleagues in the College of Business and inquiries with assessment specialists, advisory board members, and textbook publisher representatives yielded the first list of potential simulations. After a series of presentations by Harvard Business School and other presenters, the team refocused their review of simulations with the development of a set of criteria that would be used to assess the viability of simulations.

Each committee member was assigned several simulations to review and report back to the group. This process was implemented to speed up the simulations review process. Dividing up the simulations among group members was more efficient, but not highly effective in terms of thoroughness of review. It takes several hours and often training by the simulation provider in order to ascertain the effectiveness of using a particular simulation.

One weakness of assigning the simulations to one or two individuals for review was that the team often had questions about the simulation that the reviewers had not asked. Also, at one point the vendor had sold other members of the team on the usability of their simulation. When the appointed reviewers reported back favorably, other members of the team were not convinced of the findings. The simulation had to be reviewed a second time by other members of the team.

The original simulations review process and criteria were adjusted as the review process continued. Review of the first few simulations revealed additional considerations that were important in selecting the appropriate simulations. Ninety-five pieces of evidence were examined based on the five criteria for authentic assessment checklist. The results are shown in Table 4.

Table 4: Results Based on the Authentic Assessment Frequency Table

Research Item:

\begin{tabular}{|l|c|}
\hline \multicolumn{1}{|c|}{ Dimensions } & Frequency \\
\hline Task Criterion & $\mathbf{3 2}$ \\
\hline Meaningfulness and relevance in the students' eyes & 25 \\
\hline Degree of ownership of problem and solution & 3 \\
\hline Criterion at the students' educational level & 13 \\
\hline Structure of task is well-defined & 11 \\
\hline Monodisciplinary/Multidisciplinary & $\mathbf{9}$ \\
\hline Physical Context & 1 \\
\hline Similar to professional work space & 1 \\
\hline Availability of professional resources & 6 \\
\hline Similarity to professional time frame & $\mathbf{1 0}$ \\
\hline Social Context & 11 \\
\hline Individual work/decision-making & 10 \\
\hline Groups or collaborative work/decision-making & $\mathbf{9}$ \\
\hline Result/Form & 4 \\
\hline Demonstration of competence & 1 \\
\hline Presentation to others & 4 \\
\hline Multiple indicators of learning & $\mathbf{6}$ \\
\hline Criteria & 8 \\
\hline Based on criteria in professional practice & 11 \\
\hline Related to realistic products/processes & \\
\hline Transparent and explicit & \\
\hline Criterion-referenced leading to profile score & N/A \\
\hline
\end{tabular}




\section{INTERPRETATION OF THE FINDINGS}

The major focus of the committee was on the tasks that students completed as part of the simulation. Educational level was established as a criterion for review early in the process eliminating the need to discuss it frequently. Physical aspects of the simulation and experience were the least discussed element of authentic assessment. The setting for tasks was defined by the university's delivery method. There was little discussion of physical setting because it was assumed that all students would complete tasks in their homes. Although professional time frame was discussed briefly, the committee was focused on providing a learning experience for students rather than matching the professional time frame for tasks. The definition of professional space is evolving. Many professionals work from home with a desk and computer. E-mail and documents revealed a concern on the part of the committee around how to facilitate group work in an online setting. The committee acknowledged that group work was an important component of success in business, but communications indicate that the logistics of measuring student achievement in group decision-making was difficult in an asynchronous, online classroom.

Analysis indicates results were included in the simulation evaluation checklist, but e-mail was infrequently used to discuss the analysis. This was surprising since results would be used as the summative assessment. Researchers believe that because results were included in the evaluation checklist, there was little need to discuss results outside of the checklist. The frequency of discussion of criteria elements was low. The researchers believe that this element was not discussed because of early assumptions made by the group that all simulations needed to produce an experience that mimicked professional practice.

Simulations are great tools for helping student master knowledge and skills and they work well as formative assessments. Completing simulations helps students to check their progress toward mastering workplace competencies. There is little evidence that business simulations currently available in the marketplace are structured such that they can be used as summative assessments in college courses. Simulations provide computer based training and practice opportunities for students; however, the structure of the simulations reviewed did not include summative assessment measures for evaluating student learning.

\section{IMPLICATIONS FOR FUTURE STUDY}

For non-traditional college students with below average computer skills, completing simulations may be formidable. Mastery of the computer and the logistics of using simulation software may force students to focus more on simulation navigation than on learning and demonstrating competency. Providing technical support for students will be critical to student success with simulations. In addition to technology skills, students will also need problem sovling skills and critical thinking skills prior to attempting simulation type learning (Petrakou, 2010). Simulations require that students demonstrate practical skills in business and although learning takes place during the simulation process, most students will need significant background in the course content as well as how to perform higher level Bloom's level skills to successfully pass the simulations.

Although the five elements of authentic assessment created a framework for evaluating the viability of simulations as authentic assessment techniques, there were several additional criteria that the committee judged as being important to the selection and use of a simulation. To be a viable assessment tool, simulations would need to have a revision schedule and the data elements would need to be changed on a regular basis to deter academic dishonesty. Too often, answer keys and copies of tests are circulated on the internet. Simulation costs are another concern expressed by the faculty committee. For the university to assess student learning using simulations, the costs of using simulations would have to be reasonable.

Ease of access was an important consideration when evaluating the simulations. The university enrolls students from across the United States and it was important that students were able to easily access the simulations. Technology support was an important consideration for the business curriculum committee as these simulations would be used asynchronously with online students who need accessible technical support. The ability to integrate simulations into the university's learning management system was important. Output results and the timing of output was a consideration for students and faculty. The committee considered timely feedback as important to the student evaluation and learning processes. 
University administrators were concerned that simulations costs might increase assessment costs. The benefits of using simulations needed to exceed added costs for delivering assessments. Authentic assessments are only viable if they can be developed and delivered in a cost effective manner. Estimating costs to develop authentic assessments is difficult but research suggests that the direct and indirect costs of developing authentic assessments is twice as much as traditional assessment development (Rothman, 1995; Hardy, 1995; Wiggins, 1990), Simulation costs were a consideration for the committee. The university enrolls several hundred students in the business program and the per-student cost of accessing the simulation and the costs for tailoring the simulation to the business learning outcomes were considered by the curriculum committee.

When evaluating the simulations, the committee found that the simulations were written at many different levels. From rudimentary business skills to sophisticated business decisions requiring significant analysis and evaluation of information, simulations cover a broad range of academic levels. For committee members assessing the level of simulation could be time consuming due to a lack of supplementary materials. Higher level simulations provided robust learning materials including readings, supplemental resources, and associated websites.

A conceptual framework and supporting learning materials are necessary for simulations to support student learning at the college level. Simulations allow students to interact with complex systems and ideas but assessing the actual learning that takes place can be challenging (Frezzo, Behrens, \& Mislevy, 2010). Finding an effective instructional model which supports both hard (technical or procedural) and soft (people, communication) skills can be challenging as the soft skills are more difficult to quantify.

\section{CONCLUSION}

Simulations are computer-based tools that provide opportunities for students to practice real-life skills that they need to be successful in the workplace (Wiggins, 1990). No longer limited to primarily aviation and medical education, the number of simulations and computer based training tools for business practitioners is increasing. Using simulations in the online classroom works pedagogically for skill building or formative assessment where students can use results of simulations to self assess their progress in mastering real world skills. Authentic assessment advocates who argue that conventional measurement practices emphasize passing a test rather than demonstration of real world skills would find simulations to be more authentic measurements of student learning (Tanner, 2001). The findings in this study do not contradict indications that simulations are more authentic assessments of real world skills; however, the findings indicate that simulations are not designed for the sole purpose of assessing the competencies of business students. At the present time, off-the-shelf business simulations fall short in the measurement of student learning at the summative assessment level. As the number and types of simulations and gaming applications for business professionals continue to increase, added features that allow for the measurement of student competencies will create more accurate assessment tools and more authentic assessment strategies.

\section{AUTHOR INFORMATION}

Dr. Patricia Neely has an Ed.D from the University of Virginia, an MBA from Averett University and a BS degree from Radford University. Dr. Neely has a rich background in higher education administration including curriculum design and development, program management and faculty supervision roles. Her work experience includes a number of leadership roles at Western Governors University, Old Dominion University, Kaplan University and Bluefield College. She is currently a part-time faculty member at Ashford University, manages a higher education consulting firm, and resides in Blue Ridge Mountains with her family. E-mail: tprneely@ hotmail.com

Dr. Jan Tucker has a PhD in Business Management from Northcentral University, an MBA from Florida Institute of Technology and a BA degree from Auburn University. Dr. Tucker has over 20 years experience in higher education in the areas of instruction and curriculum development. In addition, she spent over 10 years as a Human Resources consultant for several Fortune 500 companies. Her research interests include the integration of technology in education and change management processes. She teaches for Ashford University and resides in Tampa, Florida with her family. E-mail: JPTucker@tampabay.rr.com. Corresponding author. 


\section{REFERENCES}

1. Abou-Elhamd, K., Al-Sultan, A., \& Rashad, U. (2010). Simulation in ENT medical education. Journal of Laryngology \& Otology, 124 (3), 237-241.

2. Bell, H. H. \& Waag, W. L. (1998). Evaluating the Effectiveness of Flight Simulators for Training Combat Skills: A Review. The International Journal of Aviation Psychology, 8(3), 223-242. doi:10.1207/s15327108ijap0803_4

3. $\quad$ Clapper, T. (2010). Role play and simulation. Education Digest, 75 (8), 39-43.

4. $\quad$ DiMartino, J., \& Castaneda, A. (2007). Assessing Applied Skills. Educational Leadership, 64 (7), 38-42.

5. $\quad$ Epstein, J. (2010, April 21). Going Ahead with Gainful Employment. Retrieved August 21, 2010, from Inside Higher Ed: http://www.insidehighered.com/news/2010/04/21/gainful

6. Frezzo, D., Behrens, J., \& Mislevy, R. (2010). Design Patterns for Learning and Assessment: facilitating the Introduction of a Complex Simulation-Based Learning Environment into a Community of Instructors. Journal of Sicent Education \& Technology, 19 (2), 105-114.

7. Gabric, D. \& McFadden, K.L. (2001). Student and employer perceptions of desirable entry-level operations management skills. American Journal of Business, 16(1), 54-57.

8. Germain, L. (2009, December 06). Global: MBA still in demand despite recession. University World News, Issue 104. Retrieved from http://www.universityworldnews.com/

9. Gulikers, J.T., Bastiaens,T.J., \& Kirschner, P.A. (2004). A five-dimensional framework for authentic assessment. Educational Technology Research and Development 52: 67-85

10. Hardy, J. L. (1995). Assessment of the level of the actual and desirable levels of computer literacy, usage and expected knowledge of undergraduate students of nursing. Medinfo, 8(Pt. 2), 1326-1330.

11. Heather, C. (2010). Simulation labs give 'real world' experience. Oklahoma City: Journal Record, The (Oklahoma City, OK),

12. Jeffries, P. R. (2005). A Frame Work for Designing, Implementing, and Evaluating Simulations Used as Teaching Strategies in Nursing. Nursing Education Perspectives , 26 (2), 96-103.

13. Klassen, K., \& Willoughby, K. (2003). In-class simulation games: assessing student learning. Journal of Information Technology Education , 2, 1-13.

14. Newman, J., Irwin, R., Klenosky, D., \& Gillentine, A. (2003). Integrating fantasy sport play simulation into the sport management curriculum: An orientation and empirical evaluation. International Journal of Sport Management, 4 (2), 130-144.

15. Nisson, B. (2003) Teaching at its best. Hoboken, NJ: Jossey-Bass Inc.

16. Owyang, J. (2010, Septemeber 30). Upcoming research teaser: What do employers want in a corporate social media strategist? Retrieved November 2, 2010 from http://www.webstrategist.com/blog/2010/09/30/research-what-do-employers-want-in-a-corporate-social-media-strategist/

17. Palm, T. (2008). Performance assessment and authentic assessment: A conceptual analysis of the literature. Practical Assessment, Research \& Evaluation Journal, 13(4), 1-11.

18. Petrakou, A. (2010). Interacting through avatars: Virtual worlds as a context for online education. Computers \& Education, 54 (4), 1020-1027.

19. Rieber, N., Betz, L. E., Muth, E., Nikendei, C., Schrauth, M., \& al., e. (2009). Effects of medical training scenarios on heart rate variability and motivation in students and simulated patients. . Medical Education, 43 (6), 553-556.

20. Robbins, S.P. \& Judge, T.A. (2007). Essentials of organizational behavior $\left(12^{\text {th }}\right.$ ed). Upper Saddle River, NJ: Pearson Prentice Hall.

21. Rothman, R. (1995). Measuring up: Standards, assessment, and school reform. San Francisco, CA: JosseyBass.

22. Spillane, L. (February 20, 2006). The Evidence-Base for Using Simulation in Medical Education:Selected Readings and Executive Summary. SAEM Board on Behalf of the Simulator Task Force:, (pp. 1-6).

23. Tan, K., Tse, Y., \& Chung, P. (2010). A plug and play pathway approach for operations management games development. Computers \& Education, 55 (1), 109-117.

24. Wiggins, Grant (1990). The case for authentic assessment. Practical Assessment, Research \& Evaluation, 2(2). Retrieved September 13, 2011 from http://PAREonline.net/getvn.asp?v=2\&n=2 